\title{
KAJIAN NILAI-NILAI KEARIFAN LOKAL PADA ARSITEKTUR HOTEL BINTANG DAN HUNIAN VERTIKAL DI KAWASAN CAGAR BUDAYA YOGYAKARTA
}

\author{
Muhammad Arief Kurniawan ${ }^{1}$; Chyntyaningtyas Meytasari ${ }^{2}$ \\ 1,2 Teknik Arsitektur, Universitas Teknologi Yogyakarta \\ Email: arief.kurniawan@uty.ac.id
}

\begin{abstract}
Yogyakarta City Government (Pemkot) and the surrounding Regency Government (Pemkab) get a lot of criticism from the public regarding policies that have resulted in massive vertical residential development in the form of hotels and apartments. In addition, the presence of vertical housing is also feared to have an impact on changes in community culture. This study aims to examine the extent to which local wisdom values are applied to star hotels and vertical occupancy in the Yogyakarta Cultural Heritage Area and what direction can be obtained so that star hotels and vertical housing are able to incorporate the value of local wisdom in YogyakartaThis research was conducted using the transforming tradition method. The main principles of the ATUMICS method are about regulation, combination, integration, or a mixture of basic elements of tradition with modernity. The results of the analysis found that the percentage of local wisdom in star hotels and vertical buildings in malioboro $8 \%$, Kraton $15 \%$, Puro Pakualaman 10\%, Kotagede 30\% and Kotabaru 5\%. The average of all is $13.6 \%$. This proves that the value of local wisdom in star hotels and vertical buildings is still low (below 50\%). Most star hotels and vertical buildings have not adopted the type of architecture that suits their respective regions. The total stars and vertical buildings still display modern architecture and the present as the main architecture.
\end{abstract}

Keywords: cultural heritage areas, star hotels, value of local wisdom, vertical residential

\begin{abstract}
ABSTRAK
Pemerintah Kota Yogyakarta (Pemkot) dan Pemerintah Kabupaten (Pemkab) di sekitarnya mendapatkan banyak kritikan dari publik mengenai kebijakan yang telah mengakibatkan pengembangan besar-besaran hunian vertikal dalam bentuk hotel dan apartemen. Selain itu, keberadaan hunian vertikal juga dikhawatirkan akan berdampak pada perubahan budaya masyarakat. Kajian ini bertujuan untuk menguji sejauh mana nilai-nilai kearifan lokal diterapkan pada hotel berbintang dan hunian vertikal di Kawasan Warisan Budaya Yogyakarta dan arahan apa dapat diperoleh agar hotel berbintang dan hunian vertikal dapat memasukkan nilai kearifan lokal di Yogyakarta. Kajian ini dilakukan dengan menggunakan metode transforming tradition. Prinsip utama metode ATUMICS adalah tentang pengaturan, kombinasi, integrasi, atau campuran unsur-unsur dasar tradisi dengan modernitas. Hasil analisis menemukan bahwa persentase kearifan lokal di hotel berbintang dan bangunan vertikal di malioboro $8 \%$, Kraton 15\%, Puro Pakualaman 10\%, Kotagede 30\% dan Kotabaru 5\%. Rata-rata semua adalah 13,6\%. Ini membuktikan bahwa nilai kearifan lokal di hotel berbintang dan hunian vertikal masih rendah (di bawah 50\%). Sebagian besar hotel bintang dan hunian vertikal belum mengadopsi jenis arsitektur yang sesuai dengan daerahnya masing-masing. Hotel bintang dan bangunan vertikal masih menampilkan arsitektur modern dan masa kini sebagai arsitektur utama.
\end{abstract}

Kata kunci: kawasan cagar budaya, hotel bintang, nilai kearifan lokal, hunian vertikal 


\section{PENDAHULUAN}

Yogyakarta merupakan kota dengan tingkat kepadatan pemukiman yang tinggi. Luas kota Yogyakarta sekitar 32,5 kilometer persegi dan berpenduduk 500 ribu jiwa termasuk kecil untuk pegembangan kawasan hunian pemukiman. Wilayah Kota Yogyakarta tidak terlalu luas, sehingga diperlukan konsep pertumbuhan kota yang tepat, salah satunya mengarahkan perumahan agar tumbuh vertikal seperti rumah susun atau apartemen. Berkembangnya Yogyakarta sebagai kota budaya berbasis pendidikan dan destinasi wisata turut menggeliatkan bisnis properti, terutama hunian vertikal. Pemerintah Kota Yogyakarta terus melakukan kajian pengembangan konsep pertumbuhan kota. Salah satu upaya yang dilakukan adalah mengarahkan perumahan agar tumbuh vertikal. Contoh hunian vertikal adalah rumah susum, apartemen dan kondominium. Tahun 2017 ini juga tercatat terdapat hampir 20 apartemen dan rumah susun baru yang ada di Yogyakarta. Status Yogyakarta sebagai salah satu Daerah Istimewa di Indonesia dan daerah tujuan wisata kedua setelah Bali mendorong minat pasar property seperti hotel. Hingga akhir 2016 tercatat jumlah hotel di DIY ada 87 hotel bintang dan 1.100 hotel non bintang atau melati.

Yogyakarta merupakan kota sejarah dan budaya berdasarkan bangunan yang ada di dalamnya.Menurut Pemerintah Daerah Yogyakarta, Ada tiga jenis gaya arsitektur bangunan yang diakui menjadi ciri khas Yogyakarta yakni Arsitektur Jawa, Arsitektur Kolonial atau Indische dan Arsitektur Cina. Arsitektur Jawa merupakan Arsitektur lokal dimana dulunya Yogyakarta adalah kerajaan jawa mataram yang bangunannya memilik gaya arsitektur khas arsitektur indis muncul ketika masuknya penjajah kolonial belanda ke Indonesia dengan membawa budaya dan gaya arsitektur bergaya eropa dan arsitektur cina munculnya bersamaan dengan masuknya orang china lewat jalur perdagangan. Oleh karena itu pemerintah daerah menetapkan 5 kawasan Cagar Budaya (KCB) yang ada di Yogyakarta yakni KCB Malioboro,KCB Kraton, KCB Puro Pakualaman, KCB Kotabaru dan KCB Kotagede. Penetapan ini berfungsi untuk menjaga dan melindungi cagar budaya yang ada di dalam kawasan tersebut.

Munculnya bangunan baru di Yogyakarta seperti hotel bintang dan hunian vertikal hendaknya memasukkan nilai-nilai arsitektur kearifan lokal yang ada di Yogyakarta.

Secara khusus kegiatan ini bertujuan untuk mengkaji sejauh mana nilai nilai kearifan lokal diterapkan pada arsitektur hotel bintang dan hunian vertikal yang ada di Kawasan Cagar Budaya Yogyakarta dan arahan apa yang bisa didapatkan agar arsitektur hotel bintang dan hunian vertikal mampu memasukkan nilai nilai kearifan lokal yang ada di Yogyakarta

Pertama kali konsep kearifan lokal (local genius) ini menurut Koentjaraningrat yang dikutip Kasiyan dan Ismadi diperkenalkan oleh arkeolog H.G Quaritch Wales dalam tulisannya berjudul "The Making of Greater India: A Study in South-East Asia Culture Change" yang dimuat dalam Journal of the Royal Asiatic Sociaty (1948). Ciri-ciri khas atau yang biasa disebut sebagai 'pribumi' itulah, yang oleh Wales diistilahkan 'local genius', yang di dalamnya terkandung makna sebagai 'basic personality of each culture'. Dengan mengacu pendapat Wales mengenai local genius secara luas, dapat diartikan sebagai proses cultural characteristic, yakni perkembangan dari proses fenomenologis ke sifat kognitif, memiliki dasar:

1. Menunjukkan pandangan hidup dan sistem nilai dari masyarakat (orientation).

2. Menggambarkan tanggapan masyarakat terhadap dunia luar (perception).

3. Mewujudkan tingkah laku masyarakat sehari-hari (attitude dan pattern of life). 

4. Mewarisi pola kehidupan masyarakat (life style)

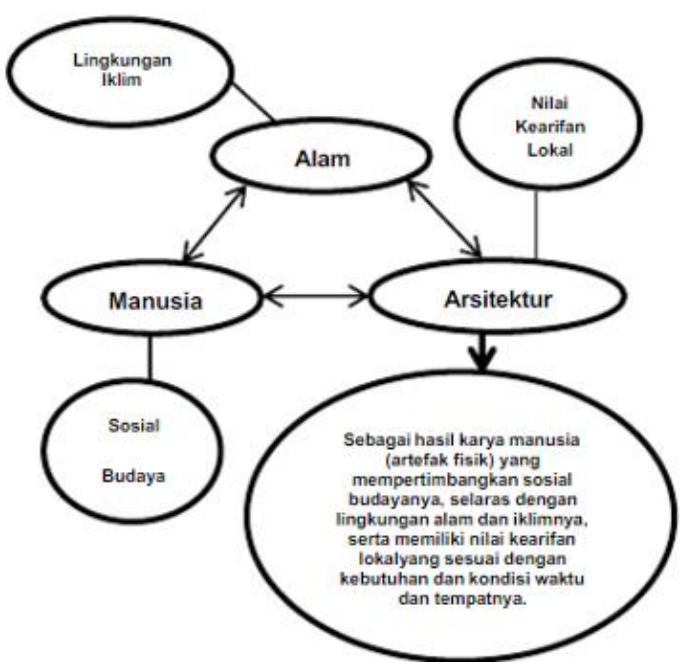

Gambar 1. Skema Hubungan Manusia, Alam, dan Arsitektur

\section{Kearifan Lokal dalam Modernitas}

Kearifan lokal merupakan bentuk sikap, pandangan dan kemampuan masyarakat didalam mengelola lingkungan rohani dan jasmaninya terhadap situasi geografispolitis, historis, dan situasional yang bersifat local (Kartawinata, 2011).

Konsepsi makna kearifan lokal tersebut merupakan kondisi ideal untuk menatap kondisi kehidupan yang lebih baik di era modern ini. Namun dalam kehidupan saat ini, manusia telah merasa bahwa dirinya modern sehingga menganggap tradisi adalah primitif dan tidak perlu dipakai. Akibatnya terdapat mata rantai yang

\section{METODE}

Pendekatan yang digunakan dalam kajian ini adalah pendekatan kualitatif. Dasar penggunaan kualitatif karena kajian ini bertujuan untuk memunculkan nilai-nilai lokal yang didapatkan dari temuan-temuan empiris (Hakim, 2003).

Kajian ini lebih memfokuskan pada katakata tertulis atau lisan dari masyarakat, perilaku yang diamati terkait lokus tempat tertentu. Menyusun asumsi dasar dan aturan bepikir yang akan digunakan dalam terputus antara hubungan manusia (sosial budaya), alam(lingkungan/iklim), arsitektur (artefak fisik), sehingga kearifan lokal mengalami perubahan makna. Pemikiran praktis seperti itu yang mengakibatkan hilangnya nilai kearifan terhadap suatu budaya. Dalam kasus di Indonesia dampak modernitas sangat terasa dilingkungan perkotaan. Hal-hal yang berbau tradisi sudah jarang ditemukan. Diperparah dengan menjamurnya perumahanperumahan yang menghadirkan konsep desain minimalis dengan estetika bentuk dan warna yang justru keliatan sangat maksimalis karena tidak sesuaidengan fungsi bahkan tidak memiliki fungsi sama sekali. Pengaruh modernitas juga sudah sampai ke wilayah-wilayah pedesaan.

Beberapa mengganti dengan konsep modern tetapi pada tatanan nilai tradisi, dan ada juga yang mengganti dengan konsep modern tetapi tetap pada tatanan nilai tradisi. Semua akibat dari factor ekonomi yang terus meningkat sehingga memperlihatkan status sosialnya. arsitektur lokal yang kaya nilai-nilai kearifan lokal lebih teruji karena telah diwariskan sejak ratusan tahun lalu. Para leluhur telah melakukan serangkaian proses rancang bangun hunian secara trial and error sampai mendapatkan bentuk hunian paling pas dan nyaman dengan kondisi di wilayah setempat.

kajian merupakan proses awal. Kemudian asumsi dan aturan berpikir tersebut diterapkan secara sistematis dalam pengumpulan dan pengolahan data untuk memberikan penjelasan dan argumentasi.

Lokasi kajian ini terletak pada lima kawasan cagar budaya yang ada di Yogyakarta yakni Kawasan Cagar Budaya Malioboro, Kraton, Pakualaman, Kotabaru dan Kotagede dimana di lima kawasan tersebut jika 
terdapat hotel bintang dan hunian vertikal seperti apartemen.

Teori Transforming Tradition kajian menggunakan teori Transforming Tradition yang dikembangkan oleh Adhi Nugraha. Teori ini dikembangkan dalam rangka upaya memelihara tradisi yang diaplikasi dalam konteks desain. Metode yang digunakan dalam teori Transforming Tradition ini sebagai parameter pengendali untuk melihat bentuk transformasi dari teori Transforming Tradition adalah metode ATUMICS. ATUMICS adalah singkatan dari Artefact- Technique -Utility- Material-IconConcept-Shape. Prinsip utama metode ATUMICS adalah tentang pengaturan, kombinasi, integrasi, atau campuran antara unsur-unsur dasar tradisi dengan modernitas.

1. Artefact (A), mengacu pada suatu objek yang merupakan pusat dari penelitian ini, yaitu bangunan hunian vertikal yang ada di Yogyakarta. Enam kata yang lainnya, yaitu Technique (T), Utility (U), Material (M), Icon (I), Concept (C), dan Shape (S) mencerminkan enam elemen dasar dari artefak/ obyek penelitian.

2. Technique (T), teknik menjelaskan mengenai segala jenis pengetahuan teknik, seperti teknik pembuatan, teknik produksi, atau bagaiman akhirnya artefak terbentuk baik melalui proses, sejarah, maupun hal-hal lain yang mempengaruhinya. Teknik berarti juga teknologi, yang mengacu pada semua sarana dan proses dalam mewujudkan memanfaatkan potensi yang ada.

3. Utility (U), pengertian utility (utilitas) digunakan sebagai alat fungsional untuk suatu benda. utilitas atau fungsi telah selalu terhubung dengan form. Melihat dari pengertian semantik, fungsi memiliki dua pengertian yaitu dalam konteks kegunaan dan konteks produk/benda. Sebagai contoh kursi ukir, dalam kontek produk/benda maka kursi berfungsi sebagai sarana untuk duduk, dan dalam konteks kegunaan lainnya kursi yang dibuat dengan karya seni ukir kualitas tinggi akan menunjukkan kelas atau tingkatan dari penggunanya.
4. Material (M), istilah 'material' mengacu pada setiap bentuk fisik dari hal-hal yang dapat dibuat. Dalam bidang arsitektur dan interior, pengertian biasanya ditekankan pada hasil akhir dari suatu objek benda/ produk, atau bangunan (kursi, meja, pintu, ukiran, dinding, lantai, dsb).

5. Icon (I), icon, dalam kajian ini menunjuk kepada bentuk-bentuk simbolis yang mana dapat bersumber dari alam (flora dan fauna), geografi, ornamen, dekorasi, warna, mitos, orang, dan artefak. Peran elemen 'ikon' adalah untuk memberikan tanda ikonik dan makna simbolik suatu benda.

6. Concept (C), pemahaman 'konsep' mengacu pada faktor-faktor yang melatarbelakangi terbentuknya suatu objek. Konsep dapat diukur secara kualitatif, seperti kebiasaan, norma, kepercayaan, karakteristik, perasaan, emosi, spiritualitas, nilai-nilai, ideologi, dan budaya.

7. Shape (S), shape mengacu pada bentuk, performa, dan sifat visual dan fisik dari suatu obyek, yang termasuk didalamnya menganalisa tentang ukuran dan proporsi.

Data yang dikumpulkan, meliputi:

Data sekunder

1. Peraturan perundang-undangan tentang Hunian vertikal di Yogyakarta

2. Peraturan perundang-undangan tentang Desain Arsitektural bangunan di Yogyakarta

3. Rencana Tata Ruang Kota Yogyakarta

4. Studi-studi di sekitar lokasi yang pernah dilakukan oleh instansiinstansi terkait.

Data primer

1. Data inventarisasi hotel bintang dan hunian vertikal di Kawasan Cagar Budaya Yogyakarta (Malioboro, Kraton, Pakualaman, Kotabaru dan Kotagede).

2. Data Arsitektural dan Interior Hotel Bintang dan Hunian Vertikal di di Kawasan Cagar Budaya Yogyakarta 


\section{HASIL DAN PEMBAHASAN}

Masing-masing akan dibahas tentang hotel bintang dan hunian vertikal di kawasan cagar budaya yang ada di Yogyakarta

\section{Kawasan Cagar Budaya Malioboro}

Di Kawasan Cagar budaya Malioboro terdapat 29 hotel bintang yang terdata berdasarkan hasil survey di lapangan. Di kawasan cagar budaya Malioboro Paling banyak diantara kawasan cagar budaya yang lain. Berdasarkan aturan peraturan daerah tentang kawasan cagar budaya bahwa kawasan cagar budaya Malioboro mempunyai Gaya Arsitektur Indis dan Cina.

Berdasarkan hasil survey didapatkan hasil bahwa ada beberapa hotel yang masih kurang sekali mengadopsi gaya arsitektur yang sesuai kearifan lokal yakni indis maupun cina seperti hotel Dafam Fortuna, hotel Pyerenees, hotel Cordela Kartika Dewi, Zamrud Malioboro, Mataram 2 Malioboro, The Cabin Hotel, Malioboro Palace, Grand Puri Saron Boutique Hotel, Hotel Pop, Hotel Pesona Malioboro, Kreshna guest House, Hotel Blue Safir, Hotel Grand Zuri, Griya Hotel Jogja, Hotel Poncowinatan, Uniq Hotel, Malioboro Garden Hotel, Hotel Abadi Jogja.

Hotel Mutiara, New Hotel Lilik, Nueve Malioboro Hotel, Hotel Jentra Malioboro, Hotel Batik Yogyakarta, Hotel RedDoorz memiliki kearifan lokal yakni mengadopsi gaya arsitektur indis dan cina yang ada di kawasan cagar budaya Malioboro walaupun nilainya tidak besar. Gaya arsitektur ini lebih terlihat pada ornamen bangunann dan bentuk bangunannnya yang kokoh, kolom, dinding besar, seperti pada arsiktetur indis dengan bukaan jendela yang besar.

Berdasarkan hasil analisa dengan atumics prosentase kearifan lokal hotel bintang yang ada di kawasan cagar budaya Puro Pakualaman adalah 10\%.

\section{Kawasan Cagar Budaya Kraton}

Di Kawasan Cagar budaya Kraton terdapat 3 hotel bintang yang terdata berdasarkan hasil survey di lapangan yakni Amanda hotel, hotel Neo Awana dan The Cube hotel. Berdasarkan aturan peraturan daerah tentang kawasan cagar budaya bahwa kawasan cagar budaya Kraton mempunyai Gaya Arsitektur Jawa.

Amanda Hotel Bangunan hotel dengan tipe hunian tropis dengan atap dak beton dan gunungan pada entrance hotel, fasad berornament cirikhas ukiran khas mataram kuno. Material struktur utama beton bertulang, dinding batubata dan dengan finishing pernis dan juga kayu jati ukir pada fasad maupun interior. Hotel ini penuh dengan kearifan lokal yakni gaya arsitektur jawa.

Hotel Neo Awana adalah Bangunan hotel dengan bentuk kubisbe beratap datar/dak. Memiliki ciri khas penggunaan roster pada muka bangunan sebagai secondary skin. Material konvensional modern seperti kayu, keramik, hpl, kaca, dll. Kearifan lokal pada hotel ini tidak ada karena lebih banyak menampilkan bangunan modern. Kearifan lokal arsitektur jawa pada hotel ini masih kurang.

The Cube Hotel adalah hotel dengan Bangunan rendah dengan 5 lantai dengan menggunakan atap plat beton dan struktur beton berulang. Material dan furnitur modern. Kearifan lokal tampak pada atap limasan pada hotel dan penggunaan material lokal yakni batu alam. Kearifan lokal arsitektur jawa pada bangunan ini masih kurang

Berdasarkan hasil analisa dengan atumics prosentase kearifan lokal hotel bintang yang ada di kawasan cagar budaya Kraton adalah $15 \%$. 


\section{Kawasan Cagar Budaya Puro Pakualaman}

Di Kawasan Cagar budaya Puro Pakualaman terdapat 2 hotel bintang yang terdata berdasarkan hasil survey di lapangan yakni Jambuluwuk hotel dan hotel Zest. Berdasarkan aturan peraturan daerah tentang kawasan cagar budaya bahwa kawasan cagar budaya Puro Pakualaman mempunyai Gaya Arsitektur Jawa.

Jambuluwuk hotel kearifan lokal masih kurang, bangunan dengan ciri khas bentuk kubisme dengan bukaan banyak dan teratur memenuhi muka bangunan. Kombinasi konsep modern yang diterapkan pada kulit dan struktur bangunan dan dengan percampuran konsep tradisional sebagai ornament. Ornamen interior Pada bangunan tersebut banyak menggunakan ornamen-ornamen budaya jawa seperti tokoh wayang dan gunungan di dalam interior bangunan tersebut dan seperti ukiran-ukiran di dalamnya, sehingga menggambarkan budaya Jawa. Kearifan lokal arsitektur jawa pada hotel bintang ini masih kurang.

Hotel zest merupakan Bangunan rendah dengan 5 lantai dengan menggunakan atap plat beton dan struktur beton berulang Material dan furnitur modern yang sederhana.Di hotel zest kearifan lokal kurang sekali karena dari segi bangunan dan interior dalamnya menggunakan gaya arsitektur modern.

Berdasarkan hasil analisa dengan atumics prosentase kearifan lokal hotel bintang yang ada di kawasan cagar budaya Puro Pakualaman adalah 10\%.

\section{Kawasan Cagar Budaya Kotagede}

Di Kawasan Cagar budaya Kotagede terdapat 3 hotel bintang yang terdata berdasarkan hasil survey di lapangan yakni hotel Ros In, hotel Kalya dan hotel Bifa. Berdasarkan aturan peraturan daerah tentang kawasan cagar budaya bahwa kawasan cagar budaya Kotagede mempunyai Gaya Arsitektur Jawa.
Hotel ros in tipe bangunan bertingkat sedang dengan system struktur rangka aku beton bertulang. serta Baja konsvensional dan Baja Ringan. Kesan modern terlihat dari hotel ini. Struktur Baja Konvensional yang di selimuti beton serta ACP bermotif tertentu dengan modul yang beraturan sebagai penutup dinding, kombinasi kayu sebagai dekorasi dan batu marmer untuk ornament pendukung serta kaca pada bukaan. Ornament, pada bangunan tersebut banyak menggunakan ornamen- ornamen gerabah dan juga batik parang khas jogja. Dan alat music khas jawa (gamelan) terdapat di hall. Konsep Hitech pada Eksterior bangunan dipadukan dengan dekorasi interior yang memasukkan unsur Jawa berupa patung, ukiran dan gamelan. Kearifan lokal bangunan jawa pada bangunan ini masih kurang, karena lebih banyak menggunakan gaya arsitektur modern walaupun gaya arsitektur jawa dimasukkan namun belum begitu banyak.

Hotel Kayla Bangunan hotel yang mengungsun konsep Modern fun dengan bangunan kotak memanjang kebelakang. Corak tradisional hanya nampak dari fasad bangunan yang bermotif batik. Ornamen bangunan hotel ini bercirikhas batik motif kawung unsur motif geometris yang dan terdapat juga motif batik lainnya didalam interior hotel seperti pada bagian dinding, dan Hpl meja yang bermotif batik. Dan warna keseluruhan bangunan yaitu perbaduan 3 unsur warna yang saling bersinergi abu abu, kuning dan coklat. Kearifan lokal arsitektur jawa pada bangunan ini masih kurang.

Berdasarkan hasil analisa dengan atumics prosentase kearifan lokal hotel bintang yang ada di kawasan cagar budaya Kotagede adalah $30 \%$.

\section{Kawasan Cagar Budaya Kotabaru}

Di Kawasan Cagar budaya Kotabaru terdapat 2 hotel bintang yang terdata berdasarkan hasil survey di lapangan yakni hotel Graha Kinasih dan hotel Fave Malioboro. Berdasarkan aturan peraturan daerah tentang kawasan cagar budaya 
bahwa kawasan cagar budaya Kotabaru mempunyai Gaya Arsitektur Indis.

Hotel Graha Kinasih adalah Bangunan hotel dengan tipe hunian tropis dengan atap limasan, fasad tanpa ornamen terbentuk dari beton precast. Tipe bangunan bertingkat rendah 2 lantai dengan struktur beton bertulang pada kolom balok dan plat. Teknik yang unik dari bangunan ini adalah penggunaan kayu jati yang diekpose pada kusen dan jendela selain itu juga pada luar plafond bangunan dengan kayu bengkirai. Mengambil konsep modern tropis dengan penggunaan warna putih dan dengan ornament jawa seperti bentuk atap limasan khas bangunan tropis dan dengan sedikit ornamen perpaduan batu alam dan kayu ekspose. Kearifan lokal bangunan indis pada bangunan ini masih kurang, karena lebih banyak menggunakan gaya arsitektur jawa. Kearifan lokal arsitektur indis pada bangunan ini masih kurang

\section{SIMPULAN}

Berdasarkan hasil analisis hotel bintang dan hunian vertikal di 5 Kawasan Cagar Budaya di Yogyakarta, dalam melihat nilai kearifan lokal yang ada dengan metode ATUMICS (Artefact, Technic, Utility, Material, Icon, Concept, Shape) diperoleh hasil sebagai berikut: 1) KCB Kraton sebesar 15\%; 2) KCB Pakualaman sebesar 10\%; 3) KCB Malioboro sebesar 8\%; 4) KCB Kotagede sebesar 30\%; dan 5) KCB Kota baru sebesar $5 \%$.

Dari hasil analisa didapatkan bahwa kesesuaian arsitektur hotel bintang dengan
Hotel Fave Malioboro adalah Bangunan hotel dengan tipe hunian modern dan terkesan fun dengan ornament fasad yang atraktif. Material struktur utama beton bertulang, dinding bata ringan dan dengan dengan finishing warna-warni pada interior yang terkesan fun. Adanya ornamen yang khas mencerminkan budaya lokal, yaitu pada ruang receptionist yang terdapat motif baik selain itu pada koridor dan interior kamar juga terdapat ornament jogja. Kearifan lokal bangunan indis pada bangunan ini masih kurang, karena lebih banyak menggunakan gaya arsitektur modern minimalis. Kearifan lokal arsitektur indis pada bangunan ini masih kurang.

Berdasarkan hasil analisa dengan atumics prosentase kearifan lokal hotel bintang yang ada di kawasan cagar budaya Kotagede adalah $5 \%$.

kearifan lokal yang ada di kawasan tersebut masih rendah yakni rata-rata $13,6 \%$ (masih dibawah 50\%). Sebagian besar hotel bintang dan bangunan vertikal belum mengadopsi jenis arsitektur yang sesuai dengan kawasan masing-masing. Hotal bintang dan bangunan vertikal masih menampilkan arsitektur modern dan kekinian sebagai arsitektur utama sedangkan arsitektur yang membawa nilai kearifan lokal hanya sebagai pelengkap dan pendukung.

Duerk, Donna P. (1993) Architectural Programming: Information Management for Design. New York: Van Nostrand Reinhold.

Correa, Charles-Ken Yeang. (1983). Architecture and Identity. Singapura: Media Itd. 
Geoffrey Broadbent. (1995). Design in Architecture http://desaingrafisindonesia.wordpr ess.com/2009/02/menggalikearifanl okalnusantara1.pdf (Diakses 10 April 2009).

Pratama, G. N. I. P., \& Sumarjo, H. (2018). Aksesibilitas Tata Letak Elevator Penumpang Gedung Kantor Pusat Layanan Terpadu (KPLT) Fakultas Teknik UNY. INformasi dan Ekspose hasil Riset Teknik Slpil dan Arsitektur, 14(1), 26-35.

Prawoto, Eko. (2009). Arsitektur Yang Memberi. http://www.scribd.com/ doc/ 73912797/ makalahekoprawoto-revisi.

Prihatmaji, Yulianto P., Perilaku Rumah Tradisional Jawa "Joglo" Terhadap Gempa, (Penelitian), Yogyakarta.
Ramadhan, M. A., Pratama, G. N. I. P., \& Hidayah, R. (2018). Penataan Sistem Jalur Pejalan Kaki di Universitas

Negeri Yogyakarta. INformasi dan Ekspose hasil Riset Teknik Slpil dan Arsitektur, 14(1), 101-117.

Sartini. (2004). Menggali Kearifan Lokal Nusantara Sebagai Kajian Filsafati. Jurnal Filsafat. 37 (2): 111-120.

Sayuti, S.A. (2005). Menuju Situasi Sadar Budaya: Antara "Yang Lain" dan Kearifan Lokal. http://www.semipalar.net. (Diakses 12 April 2009).

White, Edward T. (1975). Concept Sourcebook: A Vocabulary of Architectural Forms.Architectural Media, Tucson, Ariz. 